\title{
Conocimiento tradicional de los hongos en el occidente de Honduras
}

Elia Sarmiento, ${ }^{1}$ Gustavo Fontecha²

\section{RESUMEN}

Los hongos son los organismos eucariotas vivos más diversos y abundantes del planeta, después de los insectos. Además de su diversidad, los hongos son relevantes por su utilización cultural en todo el mundo, por tal razón, este estudio tuvo como propósito rescatar y validar las prácticas tradicionales acerca de los usos y formas de aprovechamiento de los hongos por los habitantes de las comunidades del occidente de Honduras.

Se utilizó el método de observación participante, que incluyó observación directa, encuestas, entrevistas, relatos de vida para determinar la fenología, ecología, identificación de las especies tóxicas y comestibles, formas de preparación, formas de preservación, distribución, abundancia y otros usos, origen, morfología, distribución y transmisión del conocimiento; para concluir con la taxonomía de los hongos de esta zona, apoyada en métodos clásicos y moleculares. En este estudio se describen por primera vez las especies de hongos más utilizados en el occidente de Honduras y el conocimiento que las comunidades poseen acerca de estos.

Palabras clave: hongos tóxicos, etnomicología, diversidad fúngica, hongos comestibles.

\section{ABSTRACT}

The fungi are the eukaryotic living organisms which are most diverse and abundant in the planet, after the insects. Besides their diversity, the fungi are relevant for their cultural utilization in the whole world. This study had the intention to rescue and validate the traditional practices brought from the uses and forms of utilization of the fungi by the inhabitants of the communities located in the west of Honduras. The method of participant observation was used, and it included direct observation, surveys, interviews, statements of life to determine the ecology, identification of the toxic and eatable species, forms of preparation, forms of preservation, distribution,

\footnotetext{
${ }^{1}$ Escuela de Biología, Facultad de Ciencias, UNAH. Correo electrónico: elia.sarmiento@unah.edu.hn

${ }^{2}$ Escuela de Microbiología, Facultad de Ciencias, UNAH. Correo electrónico: gustavo.fontecha@unah.edu.hn
} 
abundance and other uses, origin, morphology, distribution and transmission of knowledge; to conclude the study with the zone's fungi taxonomy based upon classic and molecular methods. For the first time, this study describes the species of most used fungi in the west of Honduras, and the knowledge the communities possess in this matter.

Key words: fungi toxins, etno-mycology, fungi diversity, eatable fungi.

\section{INTRODUCCIÓN}

Los hongos son un grupo de seres vivos con características biológicas particulares que los separan de otros taxones como animales y plantas, por eso se clasifican en un reino aparte llamado Fungi. Los hongos son seres adaptables y pueden desarrollarse casi sobre cualquier sustrato superficie, tanto en la naturaleza como en los ambientes intervenidos por el ser humano (Becker, 2006).

Desde antes del descubrimiento de la penicilina en 1929, el estudio y utilización de los hongos ocupaba ya un espacio muy importante en la mayoría de las culturas. Así, a partir del desarrollo de las ciencias experimentales, los hongos han sido objeto de estudio no solo de taxónomos y genetistas que indagan acerca de sus orígenes, formas y diversidad, sino también de químicos, bioquímicos y agrónomos que buscan obtener de ellos beneficios industriales y comerciales.

Algunos de los metabolitos que los hongos producen, se utilizan en la industria y la medicina y muchas especies son empleadas en el control biológico de vectores de enfermedades de plantas y humanos. Otros hongos se emplean en el mejoramiento de la producción de especies vegetales forestales y comestibles, en la preparación de alimentos y también como fuente alimentaria (Franco-Molano, 2000).

La investigación etnomicológica es la fuente básica que permite rescatar los usos y formas de aprovechamiento de los hongos en las diversas culturas a través del tiempo. Los conocimientos que las poblaciones humanas tienen sobre los hongos son complejos, si se considera que estos han sido adquiridos tan solo por observación directa y transmitidos de generación a generación (Morales, 2001).

Se sabe que al menos 200 especies de hongos son consumidas en México, en donde aproximadamente el $50 \%$ de esas especies son comercializadas en mercados tradicionales (Pérez Moreno, 2010). A su vez, en Guatemala se informa de al menos 70 especies comestibles de hongos (Bran, 2003). 
Las plantas y hongos de valor etnológico constituyen un legado de incalculable valor, ya que reflejan la adaptabilidad humana al ambiente agreste de los ecosistemas. En tal sentido, el conocimiento etnológico basa su importancia en que los antiguos habitantes de una región probaron casi todas las especies que crecían en las inmediaciones de su hábitat funcional, para llegar a encontrarle un uso a una especie dada.

De esta manera se determinó, concluyentemente y de manera empírica, un uso que les permitiera utilizar esas especies; pero, para llegar a esas conclusiones, muchas personas enfermaron por intoxicación moderada o grave e, incluso, en ocasiones tuvieron consecuencias fatales al consumir especies tóxicas en dosis letales.

Dado que Honduras no está fuera de este uso cultural de los hongos, se desarrolló esta investigación con el objetivo de conocer las especies de hongos que se consumen en las comunidades hondureñas con cultura micófaga en el occidente de Honduras.

\section{MATERIALES YMÉTODOS}

\section{Área de estudio}

El estudio se llevó a cabo en dos departamentos de Honduras con tradición de consumo de hongos: Intibucá (municipios de San Miguelito, Yamaranguila; y en los caseríos de Laguna Grande, El Membrillo y Los Arrayanes) y La Paz (municipios de San José, Santa Ana, Santa Elena; y en los caseríos de El Limón, Valle Paloma y Aguasina; ver figura 1).

La colecta se realizó después de las primeras lluvias del año durante los meses de mayo y junio, ya que los cuerpos fructíferos de estos hongos o setas aparecen únicamente una vez al año, durante las primeras tres semanas de la época lluviosa. Los criterios para determinar los sitios de colecta se basaron en la diversidad de especies y tradición de consumo.

Se utilizó el método de observación participante, que incluyó observación directa, encuestas, entrevistas, relatos de vida (que intentaban elaborar y transmitir la memoria personal y colectiva que hace referencia a las tradiciones de uso de las especies utilizadas a través del tiempo).

Las entrevistas fueron del tipo informal, no estructuradas y semiestructuradas e 
incluían los siguientes criterios: fenología, ecología, identificación de las especies tóxicas y comestibles, formas de preparación, formas de preservación, distribución, abundancia, otros usos, morfología, distribución y transmisión del conocimiento.

\section{Mapa 1. Sitios de colecta}
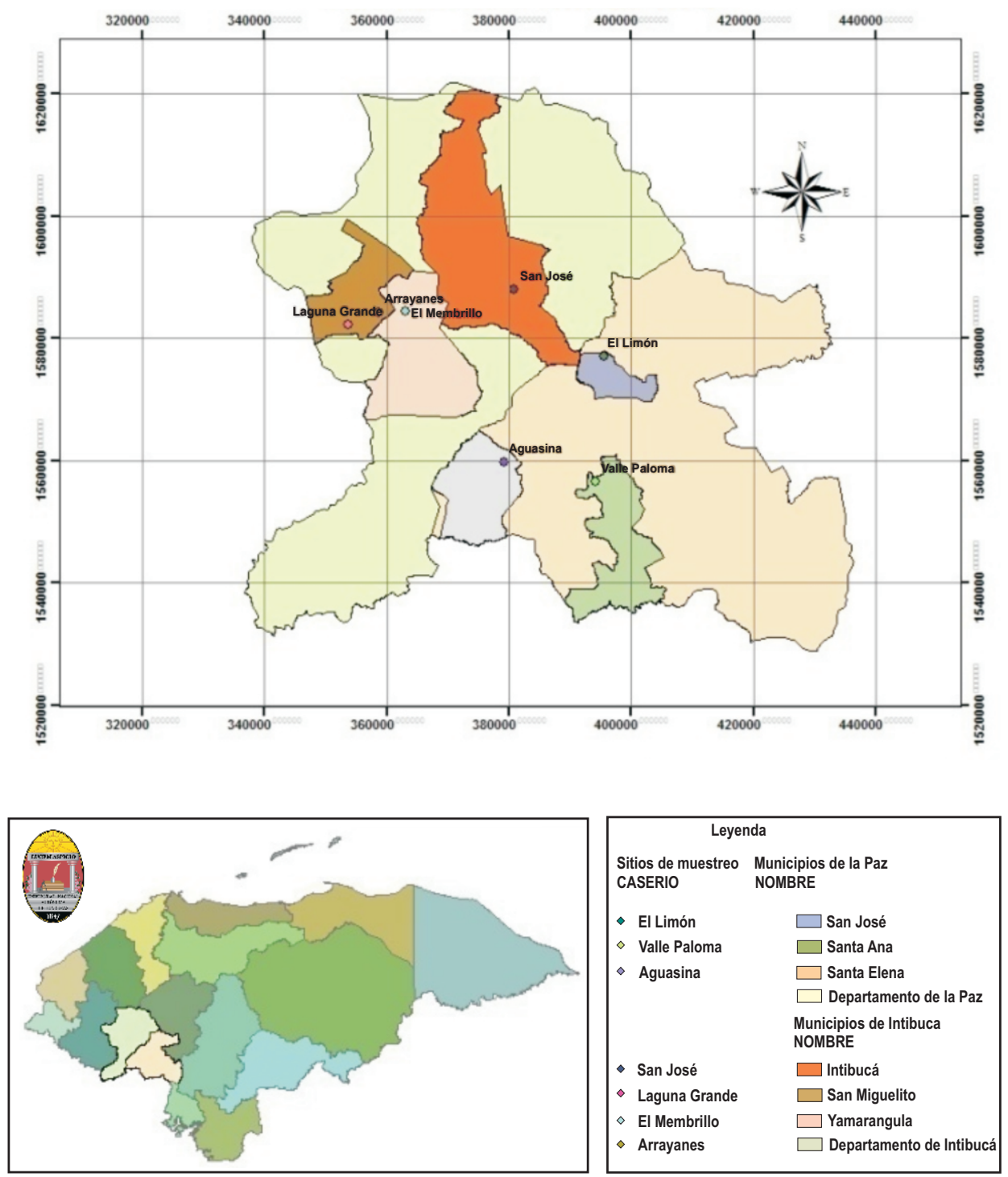

Proyección Geográfica UTM Datum WGS 84

Elaborado por G. Sandoval 


\section{Clasificación taxonómica}

Los hongos se fotografiaron y se describieron morfológicamente antes de su preservación. La clasificación de las especies fue realizada por el Osbeth Morales Esquivel, micólogo taxónomo de la Universidad de San Carlos de Guatemala, usando reactivos y claves taxonómicas. Los hongos fueron procesados y depositados en la Micoteca del Herbario Tegucigalpa Flora de Honduras (TEFH) de la Universidad Nacional Autónoma de Honduras.

\section{Caracterización molecular}

Con el objetivo de apoyar la caracterización morfológica de los individuos colectados, se analizaron dos secuencias de las regiones ribosomales del gen ITS (internal transcribed region) de las setas. Se extrajo el ADN de $100 \mathrm{mg}$ de los carpóforos congelados, usando una técnica convencional de fenol-cloroformo. El ADN extraído se almacenó a $-20^{\circ} \mathrm{C}$ hasta su utilización. Se amplificaron las regiones ITS1 e ITS2 usando cebadores específicos para el taxón de los basidiomicetes (Becerra, 2007) (ver cuadro 1).

Las amplificaciones se llevaron a cabo en un volumen final de $20 \mu \mathrm{l}$ en un Termociclador Veriti ${ }^{\text {TM }}$ 96-Well Thermal Cycler (Applied Biosystems). La mezcla de reacción contenía $10 \mu \mathrm{l}$ de PCR Master Mix 2X (Promega), $1 \mu$ l de cada cebador 10 $\mu \mathrm{M}$, agua libre de nucleasas y $1 \mu \mathrm{l}$ de ADN molde $10 \mathrm{ng} / \mu \mathrm{l}$.

El programa de la amplificación fue el siguiente: $94^{\circ} \mathrm{C}$ por $1 \mathrm{~min}, 35$ ciclos a $94^{\circ} \mathrm{C}$ por $1 \mathrm{~min}, 55^{\circ} \mathrm{C}-60^{\circ} \mathrm{C}$ por $2 \mathrm{~min}, 72^{\circ} \mathrm{C}$ por 2 min yuna extensión final $\mathrm{a} 72^{\circ} \mathrm{C}$ por $10 \mathrm{~min}$. Los productos se separaron por electroforesis de agarosa $1 \%$ con bromuro de etidio y posteriormente se purificaron mediante el kit Wizard SV Gel and PCR Purification System (Promega) y se enviaron a secuenciar (Macrogen).

Tabla 1. Secuencias de los cebadores utilizados para amplificar la región ITS ribosomal

\begin{tabular}{|c|c|}
\hline Cebador & Secuencia $\left(\mathbf{5}^{\prime} \mathbf{~} \mathbf{\prime}^{\prime}\right)$ \\
\hline ITS1F & CTTGGTCATTTAGAGGAAGTAA \\
\hline ITS2 & GCTGCGTTCTTCATCGATGC \\
\hline ITS3 & GCATCGATGAAGAACGCAGC \\
\hline ITS4 & TCCTCCGCTTATTGATATGC \\
\hline
\end{tabular}




\section{RESULTADOSYDISCUSIÓN}

Se entrevistó a un total de 106 personas, que incluyeron recolectores (adultos y niños), vendedores y consumidores de hongos. Se colectaron un total de 101 individuos, de los cuales 23 pertenecen al género Amanita (ver gráfico 1). Este género incluye numerosas especies potencialmente tóxicas e incluso letales para el ser humano; se considera que es responsable del $95 \%$ de los decesos debidos a envenenamiento por hongos.

Gráfico 1. Distribución de los hongos recolectados según su uso

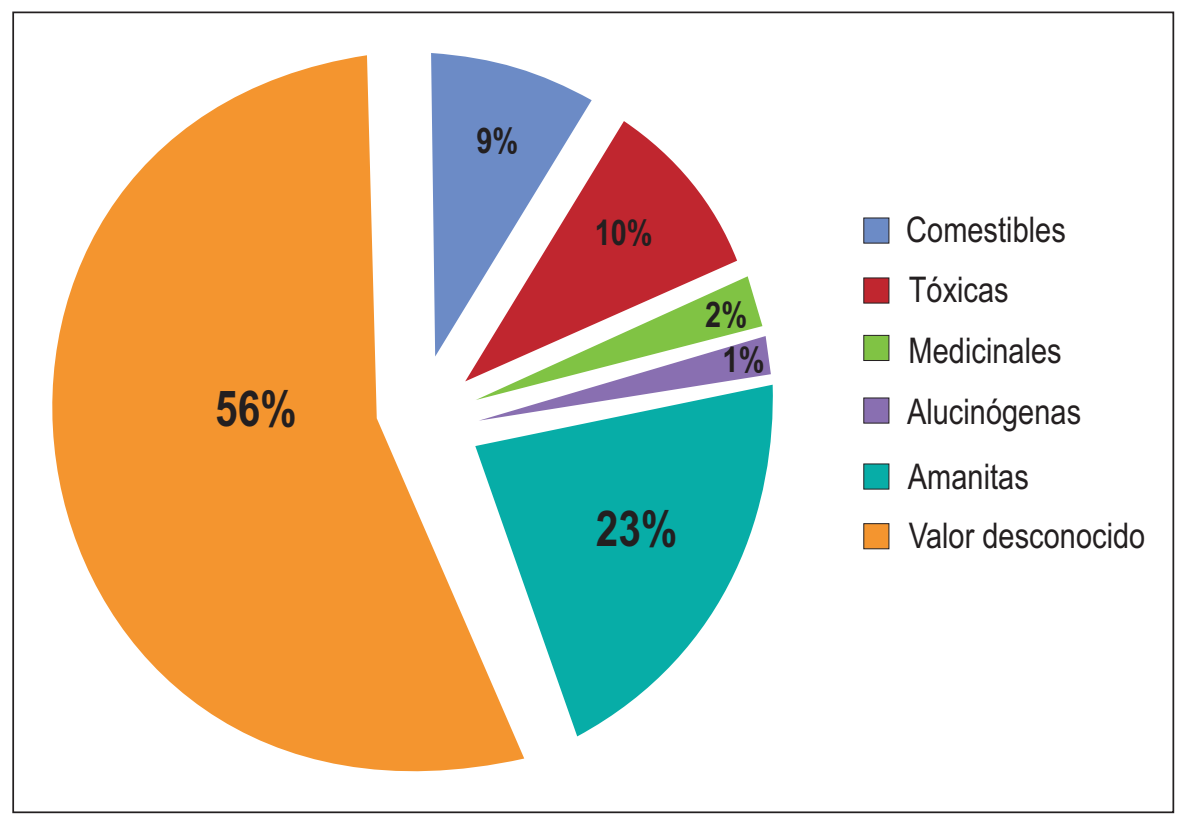

Dentro del género Amanita sobresale la especie Amanita phalloides por contribuir con la mitad de las intoxicaciones informadas. Esta es la razón por la cual las especies de hongos que pertenecen a este género se suelen conocer entre los habitantes de las regiones consumidoras como "hongos venenosos". A este género pertenece también Amanita caesarea o "la seta de los césares", que para muchos resulta ser el hongo más exquisito conocido.

La Amanita caesarea es conocida comúnmente en la región occidental de Honduras como choro sol, cumba roja o simplemente choro. Esta es la única especie explotada y comercializada en el occidente de Honduras. 
Para su comercialización se han popularizado festivales gastronómicos llamados festivales del choro, en las comunidades de La Esperanza y Cabañas, en el departamento de Intibucá.

Otras especies del género Amanita, como la $A$. Virosa, causan envenenamientos periódicos en esas regiones, debido probablemente a su similitud morfológica con A. caesarea. La A. virosa y otras especies tóxicas fueron encontradas y colectadas durante este estudio (ver tablas 2 y 3 ).

Tabla 2. Hongos comestibles en el occidente de Honduras

\begin{tabular}{|l|l|l|}
\hline Nombre científico & \multicolumn{1}{c|}{ Sustrato } & \multicolumn{1}{c|}{ Observaciones } \\
\hline $\begin{array}{l}\text { Amanita caesarea-complejo } \\
\text { Amanita rubescens } \\
\text { Boletus Pinophilus }\end{array}$ & $\begin{array}{l}\text { Suelo de bosque, formando } \\
\text { micorrizas } \\
\text { Materia orgánica } \\
\text { Materia orgánica bosque de } \\
\text { pino }\end{array}$ & $\begin{array}{l}\text { Reputación de sabor exquisito. } \\
\text { Consumirse cocido. }\end{array}$ \\
\hline Fitocybe sp. & Materia orgánica & $\begin{array}{l}\text { Farrón, crece además en } \\
\text { bosque que no sea de pino. }\end{array}$ \\
\hline Hynum repandum & $\begin{array}{l}\text { Se debe tener cuidado ya que } \\
\text { posee especies tóxicas y } \\
\text { comestibles fenotícamente muy } \\
\text { parecidas. }\end{array}$ \\
\hline $\begin{array}{l}\text { Lactarius deliciosus } \\
\text { Lactarius indigo }\end{array}$ & Sobre materia orgánica & $\begin{array}{l}\text { Se caracteriza por su carpóforo } \\
\text { grande de color blanco } \\
\text { amarillento. }\end{array}$ \\
\hline Lactarius sp. & Sobre materia orgánica & $\begin{array}{l}\text { Su sabor no amerita su nombre. } \\
\text { Se reconoce fácilmente por su }\end{array}$ \\
\hline Russula virescens & Sobre suelo & $\begin{array}{l}\text { látex azul amarillento. } \\
\text { Género muy diverso, difícil de } \\
\text { clasificar. }\end{array}$ \\
\hline & Materia orgánica & $\begin{array}{l}\text { Se caracteriza por el sombrero } \\
\text { de color verde enteramente cra- } \\
\text { quelado, carne dura, sabor dulce. }\end{array}$ \\
\hline
\end{tabular}


Tabla 3. Hongos tóxicos en el occidente de Honduras

\begin{tabular}{|c|c|c|}
\hline $\begin{array}{l}\text { Nombre } \\
\text { cientifico }\end{array}$ & Sustrato & Observaciones \\
\hline Amanita muscaria & $\begin{array}{l}\text { Suelo de bosque de coníferas } \\
\text { formando micorrizas }\end{array}$ & $\begin{array}{l}\text { Tiene efecto tanto alucinatorio como } \\
\text { venenoso, se puede confundir con } \\
\text { Amanita caesarea. }\end{array}$ \\
\hline Amanita virosa & $\begin{array}{l}\text { Suelo de bosque generalmente } \\
\text { con encinos }\end{array}$ & $\begin{array}{l}\text { Se puede confundir con género } \\
\text { Amanita de color blanco igualmente } \\
\text { mortales, como A phaloides, } A \text {. citrina, } \\
\text { también puede confundirse con espe- } \\
\text { cie del género } A \text {. garicus son volva. }\end{array}$ \\
\hline Lactarius sp. & Sin comentarios & Sin comentarios. \\
\hline Pisolthus arhizus & $\begin{array}{l}\text { Suelos arenosos asociados } \\
\text { diferentes árboles }\end{array}$ & $\begin{array}{l}\text { La bibliografía no lo reporta como } \\
\text { tóxico. }\end{array}$ \\
\hline Collybia maculata & Bosque de pino & $\begin{array}{l}\text { La bibliografía lo reporta como especie } \\
\text { sin valor (sabor amargo). }\end{array}$ \\
\hline Lactarius sp. & Materia orgánica bosque de pino & Sin comentarios. \\
\hline Boletus sp. & Materia orgánica bosque de pino & Sin comentarios. \\
\hline Collybia sp. & Materia orgánica & Sin comentarios. \\
\hline Hypholoma & Sin comentarios & Sin comentarios. \\
\hline
\end{tabular}

Conocimiento tradicional

La temporada de recolección y comercialización de hongos en la región occidental de Honduras es a inicios de la época lluviosa y dura aproximadamente un mes, dependiendo de la cantidad y los períodos de lluvia. Pero, en algunas ocasiones la aparición de las especies de hongos comestibles es escasa.

Los recolectores de hongos son principalmente agricultores o personas dedicadas a las labores domésticas, quienes desempeñan esta tarea como una segunda actividad, ya que el período de colecta es corto; no se conocen personas que se dediquen a esta actividad permanente ni exclusivamente.

Durante la temporada de aparición de las setas los recolectores suelen recogerlas durante las primeras horas de la mañana. El destino de las setas es el autoconsumo, consumo familiar (92\%) y en menor escala la comercialización en estado fresco (8\%). Algunas personas las secan o las mantienen bajo refrigeración por un máximo de dos días antes de su consumo.

Las edades de los recolectores está en un rango que va desde niños de 7 años hasta personas de más de 50 años. Se informó que el conocimiento para distinguir los hongos comestibles de los tóxicos, es usualmente adquirido de la madre o de 
amigos de los recolectores. El color es la característica que los recolectores usan para distinguir los hongos tóxicos de los comestibles según el $100 \%$ los entrevistados; en cambio, el $50 \%$ de los encuestados informa que además del color, utilizan la forma del hongo como criterio de reconocimiento.

La mayoría de recolectores y consumidores ( $80 \%$ ) dice que la razón por la que consumen setas se debe a su alto contenido nutricional; el $20 \%$ restante los consumen solamente por su sabor.

Los recolectores buscan las especies en lugares sombreados del bosque donde exista suficiente humedad, especialmente en zonas donde hay asociaciones boscosas de pino-roble. Todos los encuestados reconocen que la cantidad de hongos disminuye año con año. Esta aseveración encuentra su fundamento en el hecho de que las setas utilizables son micorrízicas y necesitan obligatoriamente vivir asociadas con plantas vasculares, como el pino, el roble o las asociaciones boscosas pino-roble; de forma que al destruirse estas especies forestales, se destruye el hábitat del hongo.

\section{Caracterización de regiones ITS ribosomales}

Se obtuvieron seis secuencias totales de la región ITS1-2 y cuatro de la región ITS34 , de seis setas reportadas como comestibles. También se obtuvieron tres secuencias ITS1-2 y cinco secuencias ITS3-4 de seis setas reportadas como tóxicas. Aunque no se trataba de un objetivo del proyecto, se obtuvieron 14 secuencias ITS provenientes de ocho especies del género Amanita que fueron colectadas en el transcurso del proyecto. Todas estas secuencias fueron depositadas en las bases de datos internacionales (NCBI Accession Numbers: HM639261-Hm639278).

Al comparar estas secuencias con las bases de datos disponibles, las setas reportadas como comestibles en la zona muestreada se asemejaban con mayor similitud nucleotídica a los géneros Lactarius deliciosus, Amanita rubescens, Amanita caesarea, Boletus pinophilus, Hydnum repandum y Clitocybe sp. En cambio, las secuencias de las setas tóxicas tuvieron mayor similitud con los géneros Amanita muscaria, Collybia sp., Boletus sp., Lactarius sp. y a un basidiomycota no especificado.

En lo pertinente al análisis de diversidad realizado entre las especies del género Amanita, los porcentajes de similitud respecto a las secuencias disponibles en las bases de datos oscilaron entre el $92 \%$ y $100 \%$. La mayoría de las secuencias 
obtenidas en este estudio no coinciden plenamente con las descritas para otras regiones geográficas, lo que sugiere que la diversidad biológica de setas en Honduras es susceptible de mayor conocimiento a futuro.

\section{CONCLUSIONES}

1. El género más explotado es "el choro" (Amanita caesarea complex), pero también pertenece a este género el hongo letal Amanita phalloides, ambos recolectados en este estudio. Al pertenecer ambos al mismo género, comparten ciertas características morfológicas que probablemente hacen que en algún momento sean confundidos por los colectores o consumidores, lo cual produce que cada año en algunas localidades se presenten problemas por intoxicación.

2. Los estudios relacionados con la diversidad fúngica son pocos, esto se debe al bajo número de taxónomos. Por tradición, los centros taxonómicos más importantes están en Estados Unidos y Europa.

3. La cantidad de hongos consumidos en el occidente de Honduras en las comunidades con cultura micófaga, no se asemeja a la gran diversidad de estas especies consumidas en México (más de 200) y Guatemala (más de 70) debido, probablemente, a la posición geográfica de estos últimos países, que por sus condiciones ambientales permite la aparición de estas especies.

4. La mayoría de las secuencias obtenidas en este estudio no coinciden plenamente con las descritas para otras regiones geográficas, lo que sugiere que la diversidad biológica de setas en Honduras es susceptible de mayor conocimiento a futuro.

\section{BIBLIOGRAFÍA}

Becerra, VMP; Rojo, C. y France, A. (2007). RAPD and ITS reveal molecular variation of Chilean populations of Beauveria bassiana. Agricultura Técnica, 67, 115-125.

Becker, G. (1989). El gran libro de setas, hongos y setas de Europa. Madrid: Susaeta ediciones.

Bran, MC. et al. (2003). Contribución al conocimiento de los hongos comestibles de Guatemala. Revista Científica, (1), 1, 24.

Franco-Molano. (2000). Setas de Colombia. Guía de campo. Antioquia: Colciencias. 
Llamas, B y Terrón. (2005). Guía de campo de la Península Ibérica. León: Celarayn Editorial.

Martínez-Carrera. et al. (1998). Canning technology as an alternative for management and conservation of wild edible mushrooms in México. Micología Neotropicalaplicada, 11, 35-51.

Martínez, J. et al. (1999). Casos clínicos: Fracaso renal agudo secundario a la intoxicación por setas. Mallorca: Servicio de Nefrología, Hospital Son Dureta.

Mata, M. (1999). Macrohongos de Costa Rica. Santo Domingo de Heredia: INBIO.

Morales. et al. (2010). Los hongos comestibles de uso tradicional en Guatemala. En Hacia un desarrollo sostenible del sistema de producción. Consumo de los hongos comestibles y medicinales en Latinoamérica. Avances y perspectivas en el siglo XXI.

Morales, O. (2001). Estudio etnomicológico de la cabecera municipal de Tecpán Guatemala, Chimaltenango. Tesis. Universidad de San Carlos. Guatemala.

Palomar, M. y Piqueras, C. (2008). Principios de urgencia, emergencia y ciudadanos críticos. Intoxicación por plantas y setas. Revista Uni-net.org.

Perez-Moreno. et al. (2010). Los hongos comestibles silvestres del Parque Nacional Izta-Popo, Zoquia pan y anexos. Estado de México: Colegio de Postgraduados, SEMARNAT, CONACYT. 